\title{
Warfarin and Ciprofloxacin Interaction: Case Report and Controversy
}

\author{
Debbie C. Byrd, PharmD, Samuel E. Gaskins, MD, Amy M. Parrish, PharmD, and \\ Lucius $B$. Freeman, $M D$
}

Warfarin is a potent anticoagulant that acts by interfering with hepatic synthesis of vitamin $\mathrm{K}$ dependent clotting factors (II, VII, IX, and X). ${ }^{1,2}$ Bleeding is the primary complication of warfarin therapy. ${ }^{3}$ A variety of drugs, including many antimicrobial agents, can increase the anticoagulant effect of warfarin. ${ }^{2,4}$ Ciprofloxacin is one antibiotic reported to influence the effect of warfarin..$^{5-10}$

Ciprofloxacin is a synthetic fluoroquinolone with a broad antimicrobial spectrum. ${ }^{11}$ Fluoroquinolones have been reported to enhance the effect of warfarin, and appropriate laboratory tests should be routinely monitored. ${ }^{12}$ The exact mechanism of the warfarin-ciprofloxacin interaction is unknown. Ciprofloxacin is postulated to affect gut flora, displace warfarin from albumin, and interfere with hepatic metabolism by inhibiting the cytochrome P-450 enzyme system. ${ }^{13,14}$

Conflicting information exists between case reports and clinical studies on the validity of the warfarin-ciprofloxacin interaction. A review of case reports submitted to the Food and Drug Administration in 1991 concluded the warfarin-fluoroquinolone interaction is clinically important and prompted recommendations for revisions in product labeling. ${ }^{13}$ Another review concluded the warfarinciprofloxacin interaction was probable. ${ }^{4}$ Yet, two clinical studies of this interaction found no notable changes in prothrombin time or international normalized ratio (INR), and no documented bleeding events. These authors concluded that a warfarin-

Submitted, revised, 25 July 1999.

From the Department of Pharmacy Practice (DCB), Auburn University School of Pharmacy, Auburn University; the Department of Family Medicine (DCB, SEG, LBF), University of Alabama, College of Community Health Sciences, Tuscaloosa; and the Department of Pharmacy (AMP), University of Alabama at Birmingham Hospital, Birmingham, Ala. Address reprint requests to Debbie $C$. Byrd, PharmD, BCPS, Department of Family Medicine, 700 University Boulevard, East, Tuscaloosa, AL 35401. ciprofloxacin interaction did not routinely occur, and warfarin therapy was not a contraindication to ciprofloxacin use. ${ }^{14,15}$ This report describes a 77-year-old man who developed a fatal intracerebral hemorrhage while taking ciprofloxacin and warfarin.

\section{Case Report}

Fifteen months before admission, a 77-year-old man's family physician prescribed warfarin $5 \mathrm{mg}$ daily for prevention of thrombosis secondary to atrial fibrillation. The patient's medical history included hypertension, benign prostatic hypertrophy, type 2 diabetes mellitus, hypothyroidism, squamous cell carcinoma of the pharyngeal wall, and coronary artery disease with three-vessel coronary artery bypass graft 1 month before admission. He had a 40-year history of tobacco use but no history of ethanol abuse. The patient's diet, with respect to warfarin, consisted of green leafy vegetables twice weekly. He was compliant with all concurrent medications including digoxin, terazosin, felodipine, quinapril, furosemide, potassium chloride, glyburide, aspirin, and levothyroxine.

During the previous 15 months, the family physician maintained the patient's prothrombin time and INR between 13.4 and 17.6 seconds, and 1.1 and 2.06, respectively. Three weeks before admission, his prothrombin time and INR were 18.1 seconds and 1.93, respectively. One month before admission, his albumin was $3.3 \mathrm{~g} / \mathrm{dL}$, and on the day of admission his liver function tests were within normal limits. Six days before admission, the patient's urologist prescribed ciprofloxacin $500 \mathrm{mg}$ twice daily for prostatitis. Subsequently, the patient came to the emergency department with profound left-sided weakness. A hemorrhage in the frontal and temporal lobes of the right cerebral hemisphere with a $10-\mathrm{mm}$ midline shift was evident on a computed tomographic (CT) scan. The patient's 
prothrombin time and INR in the emergency department were 27.2 seconds and 5.1, respectively. Within hours of arrival, the patient became comatose and died. No communication took place between the urologist and the patient's family physician; all medications were dispensed by the same pharmacy.

\section{Discussion}

Although ciprofloxacin was the only new medication added to this patient's drug regimen, two other potential warfarin drug interactions are worthy of mention: aspirin and levothyroxine. Aspirin alters hemostasis by inhibiting platelet function, thus increasing the risk of hemorrhagic complications. Levothyroxine can induce a hypermetabolic state resulting in low concentrations of coagulation factors and INR elevations. 'The clinical importance of these drug interactions appears small in the case described here. During the 15 months before the addition of ciprofloxacin, the patient's prothrombin time and INR remained stable with no report of bleeding while taking both aspirin and levothyroxine. The remaining discussion will focus on the warfarin-ciprofloxacin interaction.

Six cases reported in the literature illustrate a probable interaction between ciprofloxacin and warfarin..$^{5-10}$ These reports showed that the addition of ciprofloxacin 500 to $750 \mathrm{mg}$ twice daily for 4 to 14 days to patients on stable warfarin therapy resulted in increased prothrombin times and, on occasion, bleeding. The age range of reported patients was 48 to 88 years (mean $=71$ years). Prothrombin time elevations ranged from 22 to 135 seconds (mean 38 seconds). All patients had multiple medical problems, and all but one was taking multiple medications. Bleeding events included hematuria, hematemesis, hematochezia, and an increased tendency to bleed with venipuncture; 2 patients required vitamin $K$, and a third received a transfusion. Presumably, all patients had a concurrent infection. According to available data in the literature, the case documented herein represents the first report of a fatal hemorrhagic event related to a warfarin-ciprofloxacin interaction.

Two prospective clinical trials examined this potential warfarin-ciprofloxacin interaction. ${ }^{14,15}$ Both studies evaluated relatively few patients $(n=16$ and 36) on warfarin therapy with stable prothrombin times followed in anticoagulation clinics. Investiga- tors administered ciprofloxacin 500 to $750 \mathrm{mg}$ twice daily or placebo for 10 to 12 days and prothrombin times were compared. Prothrombin times of patients taking ciprofloxacin did not increase significantly. Patients in these trials were younger (mean age of 57 and 64 years), however, and presumably healthier than were the patients in the case reports. In both studies, none of the patients receiving ciprofloxacin actually had an infection. Both trials received financial support from Miles Laboratories.

A primary concern with the validity of case reports is that they are often confounded. Many uncontrolled variables, such as concurrent diseases, other prescribed medications, over-the-counter medications, and compliance issues, often arise. On the other hand, a consideration with the reported clinical trials is their lack of external validity. Inclusion of only a few patients, all without infection, limits the applicability of these studies. Inflammation and infection can profoundly affect hepatic microsomal enzyme activity through suppression of cytochrome P-450 enzyme expression. ${ }^{16}$ Wells and colleagues ${ }^{4}$ discuss the details of establishing a warfarin interaction. With somewhat conflicting evidence, the warfarin-ciprofloxacin interaction is designated as level 2 (probable) vs level 1 (highly probable). This designation is consistent with the Fifth American College of Chest Physicians Consensus Conference on Antithrombotic Therapy (Table 1$)^{2}$

With inappropriate use or inadequate monitoring, warfarin therapy can clearly become perilous. Warfarin use in elderly patients has increased with the indication for chronic or intermittent atrial fibrillation. ${ }^{17}$ Many of these patients have multiple medical problems and are taking complex drug regimens. It is becoming increasingly important for family physicians to monitor patients' medications closely for drug interactions, especially with respect to the possible potentiation of warfarin.

Increased vigilance concerning warfarin therapy in the elderly should occur in several areas. Education is particularly important, as patients and their families must be aware that potential drug interactions can occur. Patients should be advised to monitor for signs and symptoms of unusual or excessive bleeding. Pharmacists should alert both patients and physicians to interactions that might have been overlooked. Finally, physicians need to increase their awareness of potential warfarin-drug interac- 


\begin{tabular}{ll}
\hline Level & Medications \\
\hline 1-Highly probable & $\begin{array}{c}\text { Alcohol (if concomitant liver disease), amiodarone, anabolic steroids, cimetidine, clofibrate, } \\
\text { cotrimoxazole, erythromycin, fluconazole, isoniazid (600 mg), metronidazole, miconazole, } \\
\text { omeprazole, phenylbutazone, piroxicam, propafenone, propranolol, sulfinpyrazone (biphasic with later } \\
\text { inhibition) }\end{array}$ \\
2-Probable & $\begin{array}{c}\text { Acetaminophen, chloral hydrate, ciprofloxacin, dextropropoxyphene, disulfiram, itraconazole, quinidine, } \\
\text { phenytoin (biphasic with later inhibition), tamoxifen, tetracycline, influenza vaccine } \\
\text { Acetylsalicylic acid, disopyramide, fluorouracil, ifosfamide, ketoprofen, lovastatin, metolazone, } \\
\text { moricizine, nalidixic acid, norfloxacin, ofloxacin, propoxyphene, sulindac, tolmetin, topical salicylates } \\
\text { Cefamandole, cefazolin, gemfibrozil, heparin, indomethacin, sulfisoxazole }\end{array}$ \\
4-Doubtful &
\end{tabular}

Adapted from Hirsh et al. ${ }^{2}$

tions, and consulting physicians should always communicate with the primary care physician when medications are added to existing drug regimens.

This case report represents the most devastating outcome resulting from a potential warfarin-ciprofloxacin interaction, fatal intracerebral bleeding. Family physicians and the health care team should be aware that there are a number of medications, in addition to ciprofloxacin, that can potentially interact with warfarin. ${ }^{2,4}$ If these medications are used along with warfarin, the prothrombin time and INR must be followed closely, and the warfarin dosage adjusted appropriately.

\section{References}

1. Majerus PW, Broze GJ, Miletich JP, Tollefsen DM. Anticoagulant, thrombolytic, and antiplatelet drugs. In: Hardman JG, Limbird LE, Molinoff PB, Ruddon RW, Gilman AG, editors. Goodman and Gilman's the pharmacological basis of therapeutics. 9th ed. New York: McGraw-Hill, 1996:1341-60.

2. Hirsh J, Dalen JE, Anderson DR, Poller L, Bussey $\mathrm{H}$, Ansell J, et al Oral anticoagulants: mechanism of action, clinical effectiveness, and optimal therapeutic range. Chest 1998;114(5 Suppl):445S-69S.

3. Levine MN, Raskob G, Landefeld S, Kearon C. Hemorrhagic complications of anticoagulant treatment. Chest 1998;114(5 Suppl):511S-23S.

4. Wells PS, Holbrook AM, Crowther NR, Hirsh J. Interactions of warfarin with drugs and food. Ann Intern Med 1994;121:676-83.

5. Linville D 2d, Emory C, Graves L 3d. Ciprofloxacin and warfarin interaction. Am J Med 1991;90:765.

6. Dugoni-Kramer BM. Ciprofloxacin-warfarin interaction. DICP 1991;25:1397.
7. Kamada AK. Possible interaction between ciprofloxacin and warfarin. DICP 1990;24:27-8.

8. Johnson KC, Joe RH, Self TH. Drug interaction. J Fam Pract 1991;33:338.

9. Mott FE, Murphy S, Hunt V. Ciprofloxacin and warfarin. Ann Intern Med 1989;111:542-3.

10. Renzi R, Finkbeiner S. Ciprofloxacin interaction with sodium warfarin: a potentially dangerous side effect. Am J Emerg Med 1991;9:551-2.

11. Mandell GL, Petri WA. Antimicrobial agents. In: Hardman JG, Limbird LE, Molinoff PB, Ruddon RW, Gilman AG, editors. Goodman and Gilman's the pharmacological basis of therapeutics. 9th ed. New York: McGraw-Hill, 1996:1057-72.

12. Product information: Cipro (ciprofloxacin). West Haven, Conn: Bayer Corporation, 1997.

13. Jolson HM, Tanner LA, Green L, Grasela TH Jr. Adverse reaction reporting of interaction between warfarin and fluoroquinolones. Arch Intern Med 1991;151:1003-4.

14. Bianco TM, Bussey HI, Farnett LE, Linn WD, Roush MK, Wong YW. Potential warfarin-ciprofloxacin interaction in patients receiving long-term anticoagulation. Pharmacotherapy 1992;12:435-9.

15. Israel DS, Stotka J, Rock W, Sintek CD, Kamada $\mathrm{AK}$, Klein C, et al. Effect of ciprofloxacin on the pharmacokinetics and pharmacodynamics of warfarin. Clin Infect Dis 1996;22:251-6.

16. Morgan ET. Regulation of cytochromes P450 during inflammation and infection. Drug Metab Rev 1997;29:1129-88.

17. Laupacis A, Albers G, Dalen J, Dunn MI, Jacobson $\mathrm{AK}$, Singer DE. Antithrombotic therapy in atrial fibrillation. Chest 1998;114(5 Suppl):579S-89S. 